ISBN 978-93-84468-86-6

2016 International Research Conference on Social Sciences, Humanities and Interdisciplinary Studies

(RCSSHIS-2016)

Pattaya (Thailand) Dec. 16-17, 2016

\title{
Quality of Life for International Students Living in the Dormitory, KasemBundit University
}

\author{
Assoc. Prof. Suthum Phongsamran, and Wen Xin He \\ planning@kbu.ac.th \\ Post Graduate School of business administration \\ Kasembundit University, Bangkok
}

\begin{abstract}
The primary purpose of this study was to determine the factors that affect the quality of life forInternationalstudentsliving in the Dormitory at Kasem Bundit University.Samplings from this study were 200 International students living in the Dormitory at Kasem Bundit University by using questionnaire as a tool. The statistic applications used for this study were percentage, mean, standard deviation, $t$-test, One-way Anova, and regression analysis.

Findings indicated that the majority of respondents were females, aged 21-25 years, students coming from China, attending second year graduate school, duration of staying in Thailand between 6 months to one year, living expenses which provided by their parents around 11,000 baht per month, returning to home land twice a year, speaking and reading Thai Language is moderate, the average picture of opinions that affect the quality of life for International students Living in the Dormitory at Kasem Bundit University were in high level, such as physical and health, awareness, social environment, psychological aspects, and contiguous environment, respectively. Hypothesis testing revealed that personal different as gender, period of staying in Thailand, interval time to visit home, and ability to communicate in Thai Language affected the quality of life for International students living in the Dormitory at Kasem Bundit University. As for social aspects, such as tardiness to class, preservesanitary, modernize communication technology, and healthy and clean medical treatment with appropriate equipmentaffected the quality of life satisfaction for Internationalstudents living in the Dormitory at Kasem Bundit University atsignificantly 0.05level.

Recommendations from the study in order to make International students living in the dormitoryat Kasem Bundit Universitywith a better quality of life were service providers should educate International students to be aware of safety surrounding, living with decent physical and healthy body, notify informationand encourage International students to participate in the events and more activities held regularly. Consequently, this would developincentives andmotivation for International students living in dormitory at Kasem Bundit Universityand enhance the quality of social life.
\end{abstract}

Keywords: Satisfaction, quality of life

\section{Introduction}

As principal economist stated that the restricted amounts of inputs required by a business or economy such as motivated staff, finances, production facilities and raw materials. The social and business environment that has to deal with a scarcity situation involving limited resources tends to put pressure on affected individuals and companies. A human is considered as a type of resource, called human resources which can be managed to improve life quality, and then we called a successful management. However, physiological needs are thought to be the most important; they should be met first. Air, water, and food are metabolic requirements for survival in all animals, including humans. Clothing and shelter provide necessary protection from the elements, focus on describing the stages of growth in humans, "physiological", "safety", "belongingness" and "love", "esteem", "self-actualization", and "self-transcendence" to describe the pattern that human motivations generally move 
through.Kriangsak Charoenvongsak(2541:163) said that the country's prosperity index whenever they are concentrated with "wit" of people in that country, and "education" are the most important in determining the future outcome of a country from the above. Therefore, it's showed that education plays an important role in the development of human resources to meet the needs of the work force. Chantalak Ardharn (2555: 95) said that education is one of the indicators of the quality of people around the world. Any country has high basic education level,people who live in that country have a better life quality, such as Canada, England, and United States of America, for example. Consequently, people achieve quality of their life depend upon their education. WHOQOL (1994) defines Quality of Life as individuals' perception of their position in lifein the context of the culture and value systems which they live and in relation to their goals, expectations, standards and concerns.It is a broad ranging concept affected in away by the person's physical health, psychological state, level of independence, social relationships, personal beliefs and their relationship to salient features of their environment. The satisfaction of each person's life like there is no sickness or health issues that are barriers to education. Mental relaxation to satisfaction in the achievement of getting support from family and friends including situation awareness and satisfaction. It is vitally important that the Institute will need to study and find ways to achieve the consistency, consistency of satisfied people or students with institutions to lead to potential consequences according to the set goal, such as a good learning achievement career or a good job, etc.

Quality of student life is important part of human resources development which need to create and give directly to the needs of various organizations or are critical to economic development of all countries requirement and also important part of economic growth of the nation. Thailand will have to be prepared for human resources development, a person be required to have the knowledge, ability, expertise is not limited by the various branches, and Human beings need to have knowledge of the language and also ability to communicate with people from around the world. In order to continue strengthening the economy and to be able to compete with foreign or international level. Thailand needed to develop human resource with proper skills, talents, and also ability to communicate with people from around the world.

\section{The Purpose of the Study}

- To study the factors that affect the quality of life for international students living in the dormitory at Kasem Bundit University.

\section{Hypothesis of the study}

1. Factors of personal different affect living satisfaction of International student in dormitory at KasemBundit University.

2. Factors of quality of life relate to living satisfaction of International student in dormitory atKasemBundit University.

\section{Methodology of the Study}

The study of quality of life for international students living in the dormitory at Kasem Bundit University is the theory by relying on the concept of Campbell, UNESCO, Ferrans and Powers, andZhan.

\section{Scope of the Study}

The samples of Studies arefrom the international students who are studying in the Bachelor and master degree. Selected a sample number of 200 people, the duration of the studies performed between January-April, 2557.

\section{Data}

The questionnaires were distributed to 200International students who live in Dormitory at Kasem Bundit University. A total of 200 usable questionnaires were returned back to the researcher, yielding a 100 percent response rate. A check for missing data and validation were conducted and used data for analysis processing.

\section{Statistics Method used in the data analysis}

Descriptive statistics used in the data analysis were percentage, mean, standard deviation to describe the demographic data of the respondents and variables. Inferential Statistics used for statistical hypothesis testing used, such as t-test, One-way Anova, F-test, Regression Coefficient, Correlation Analysis, and Chi-Square. 


\section{Summary of Study Results}

The study of quality of life for international students living in the dormitory at Kasem Bundit University was to determine the factors that affect the quality of life for international students living in the dormitory at Kasem Bundit University. By using quantitative research, the independent variables were gender, aged, country that students coming from, attending what's school level, duration of staying in Thailand, living expenses which provided by whom, how much income,how often returning to home land, how well they werespeaking and reading Thai Language. The dependent variables were body's health and potential psychological aspects, social elements, and environmental aspects. Samplings from this study were 200 International students living in the Dormitory at Kasem Bundit University by using questionnaire as a tool. The statistic applications used for this study were percentage, mean, standard deviation, t-test, One-way Anova, and regression analysis. From the analysis results data can be summarizedas follows:

Findings indicated that the majority of respondents were females, aged 21-25 years, with students coming from China, attending second year graduate school, duration of staying in Thailand between 6 months to one year, living expenses which provided by their parents approximately 11,000 baht per month, returning to home land twice a year, speaking and reading Thai Language was moderate.

\section{Information concern factors that affect the quality of life of foreign students}

From the study results showed that the level of opinion towards the quality of life for international students living in the dormitory at Kasem Bundit University overview wasat high level. When considering the issue contained health, psychological, and potential of the body, environmental, social events at medium level, respectively with follows details.

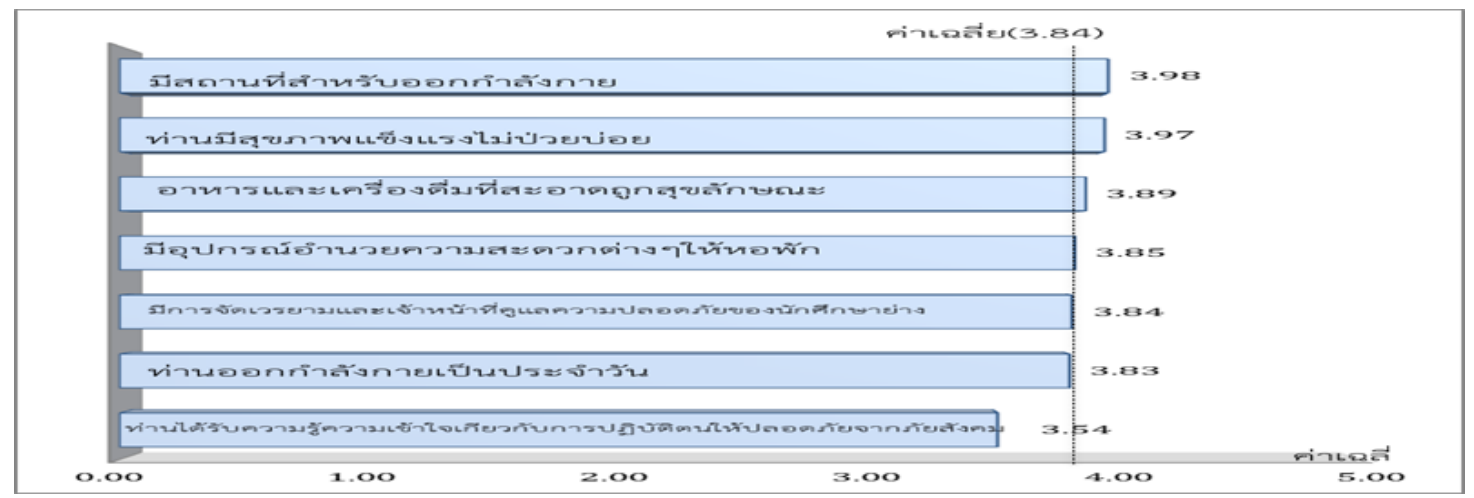

Fig. 1 The health and potential of the body aspect

Data from the study found that factors that affected the quality of life for international students living in the dormitory at Kasem Bundit University with potential of the body and health were at high level of theaverage picture $(\bar{x}=3.84)$.

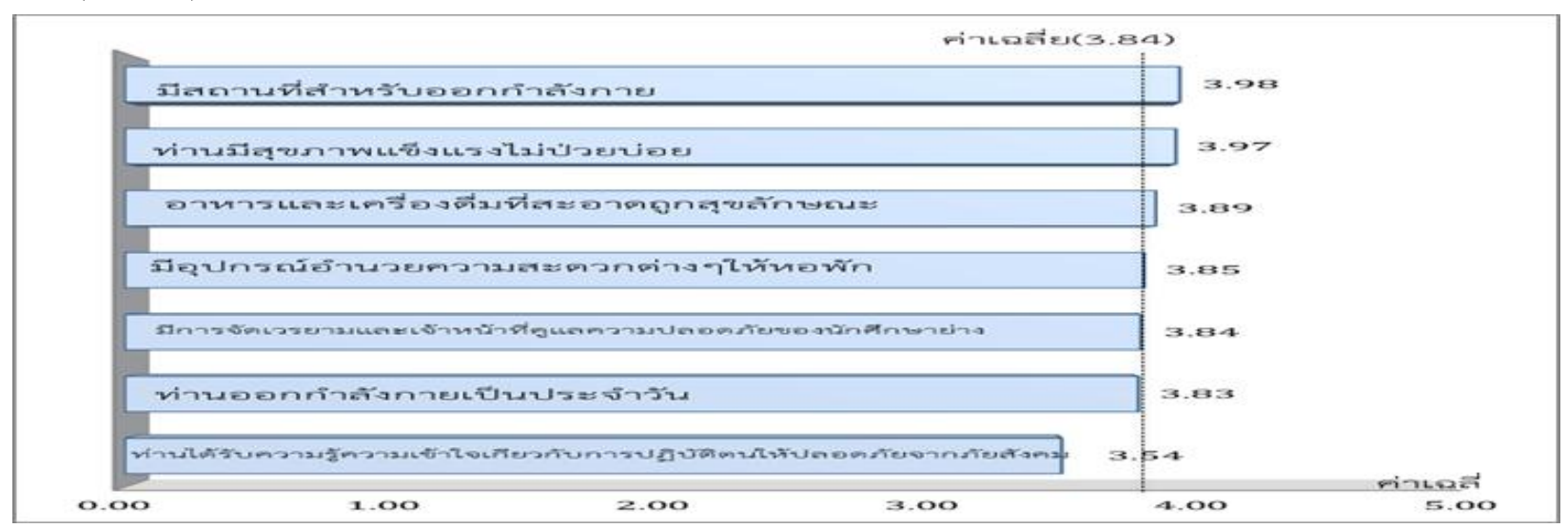

Fig. 2 Psychological aspect 
Data from the study found that factors that affected the quality of life for international students living in the dormitory at Kasem Bundit University with Psychological aspect were at high level of the average picture $(\bar{x}=3.86)$.

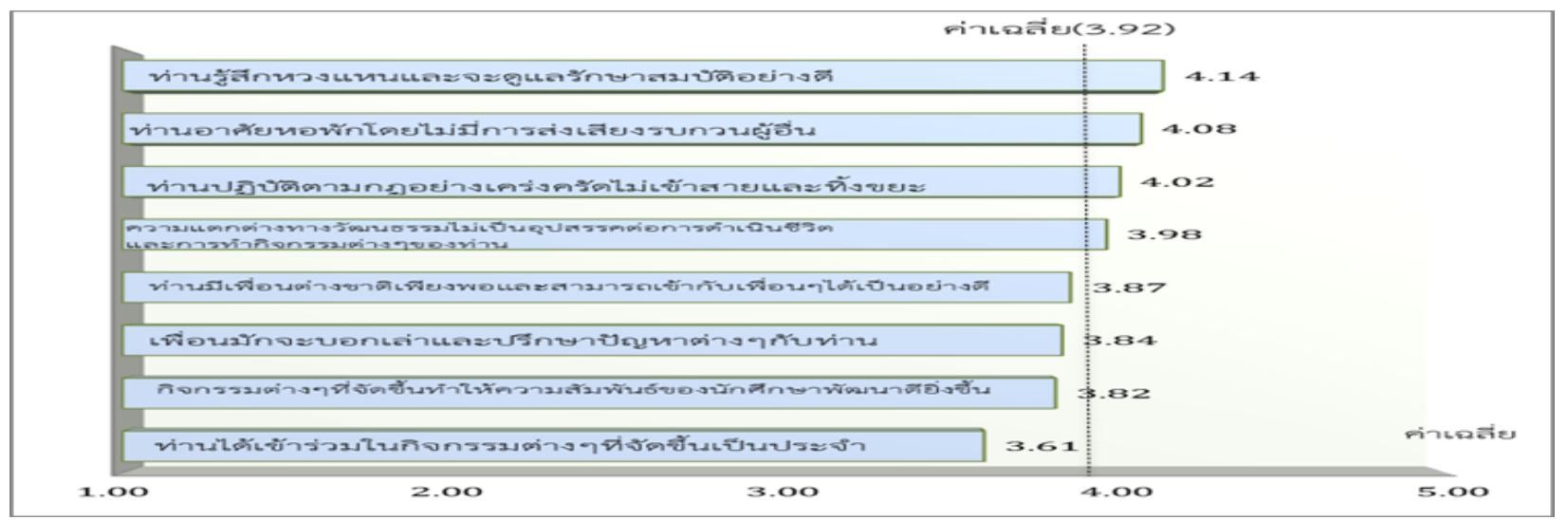

Fig. 3 Aspects of social elements

Data from the study found that factors that affected the quality of life for international students living in the dormitory at Kasem Bundit University, social element side overview were at high level of the average picture $(\bar{x}=3.92)$.

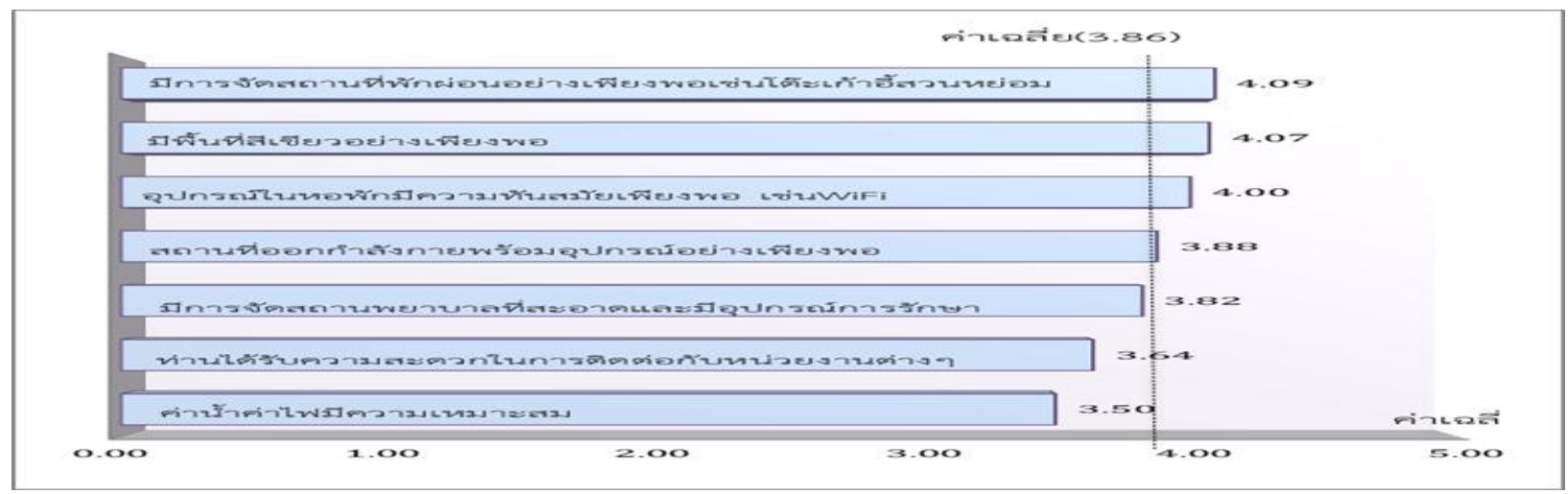

Fig. 4 Environmental aspect

Data from the study found that factors that affected the quality of life for international students living in the dormitory at Kasem Bundit University, environmental overview were at high level of the average picture $(\bar{x}=3.86)$.

\section{Discussion of Study Results}

- The study of quality of life for international students living in the dormitory at Kasem Bundit University were with the discussion as follows:

Aspects of health and body potential, an overview of the quality of life for foreign students living in the dormitory at Kasem Bundit Universitywere at high level which corresponds to Kanjana Pintakum (2551), which was a study of the quality of life for students who live in Chiang Rai Rajabhat University private-sector dormitory which levels of living satisfaction wasat high level.

As for Psychological images included the quality of life for international students living in the dormitoryat Kasem Bundit University were at high level, which corresponds to Kanjana Pintakum (2551), which was a study of the quality of life for students who live in Chiang Rai Rajabhat University private-sector dormitory which levels of living satisfaction was at high level.

Aspects of social elements, an overview of the quality of life for foreign students living in the dormitory at the Kasem Bundit University were in the high level which corresponds to Kanjana Pintakum (2551), which was a 
study of the quality of life for students who live in Chiang Rai Rajabhat University private-sector dormitory which levels of living satisfaction was at high level.

Environmental overview of the quality of life for foreign students living in the dormitory at Kasem Bundit University were at high level which corresponds to Saowaphachai Chotechoung (2550).,studied quality of life for the student who lives around the Suan Dusit Rajabhat University campus area and found that students with environmental at high level.

Satisfaction aspect, an overview of the quality of life for foreign students living in the dormitory at the Kasem Bundit University was at high level which corresponds to Saowaphachai Chotechoung (2550)., studied quality of life for the student who lives around the Suan Dusit Rajabhat University campus area and found that students with environmental at high level.

An overview of the quality of life for foreign students living in the dormitory at Kasem Bundit University was at high level which corresponds to Saowaphachai Chotechoung (2550)., studied quality of life for the student who lives around the Suan Dusit Rajabhat University campus area and found that students with environmental at high level.

\section{Recommendations from the Study}

From the study of the quality of life for international students living in the dormitory at Kasem Bundit University students have suggestions as follows:

Recommendations from the study in order to make International students living in the dormitory at Kasem Bundit University with a better quality of life were that service providers should educate International students to be aware of safety surrounding, living with decent physical and healthy body, notify information and encourage International students to participate in the events and more activities held regularly. Consequently, this would develop incentives and motivation for International students living in dormitory at Kasem Bundit University and enhance the quality of social life.

\section{Suggestion for Future Study}

Administrative officers should study quality of service of dormitory at Kasem Bundit University.

\section{References}

[1] KanjanaPintakum(2551: abstract). Quality of life for Ratchaphat Chieng Mai University studentsLiving in dormitory outside campus.

[2] KriangsakCharoenvongsak (2541). Good Governance, House of Representative documents, Thai Parliament, Thailand, Senate compound, 41 (September 2541).

[3] JamrutDuangsuwan. Self-development: self-development of human behavior.Bangkok: Institute OfRajabhat University publishing, Thonburi, 2545.

[4] PraneeRamsoot\&Jamrut Duangsuwan,Human Behavior with their Development. $3^{\text {rd }}$ edition,Bangkok: Institute of Rajabhat University, Thonburi, 2545.

[5] PriyapornVonganuroj (2547). Psychology and Human Resource administration. $7^{\text {th }}$ edition,Bangkok: Pim Dee printing co., Ltd.

[6] RojanaTaechasri (2550:14) TheTeachers Satisfaction of School Director,affiliated educational Offices district, Sa kaew, district 1.

[7] WanchaiThanawangnoi\&YongyuthPuengvongyard, Life Quality of residents in a slumPatumthani district. Bangkok: Thammasat University graduate School volunteer office, 2542.

[8] WichaiRupkamdi\&Associate.Full research report of the project“Sufficiency Economy and Community”, Bangkok: The rural Foundation of Thailand, National Institute of Development Administration, 2542.

[9] ViphapornMapopsuk. The Quality of Life Development and Society, Bangkok: Academic Support Center, 2545.

[10] VilailakTangjaroen. (2544:36-37). Households with protection for the environment. Bangkok: Tippayavisut Publisher.

[11] SiriHamsupho. Population with Quality of Life Development. Bangkok:Odian Store, 2543.

[12] SanitSirivisitkul (2550: abstract).Themeasurement ofthe quality of life for the IslamicUndergraduate students at North Bangkok College. 
[13] SittidechNilsamrit\& Associate.Research report title "Quality of Life of Thai People":results from the action of the provisions of the Constitution of the Kingdom of Thailand. Bangkok: National Institute of Development Administration Research Bureau, 2548.

[14] SuchartLakgrod\& Associate. The effect of the quality of life of workers during the economic Downturn year 2539 2541. Bangkok: Faculty of public administration, National Institute of development administration, 2541.

[15] SunthonPhetpraw (2551:17) The Teachers Satisfaction of School Director, affiliated educational Offices district, Chanthaburi district 1. Thesis work, Master of Education, Burapha University.

[16] Supannee Chai-Umporn\&SanitSamukkarn.Quality of life of Thai People study comparing Between urban and suburban in Thailand. Bangkok: National Institute of development administration, 2534.

[17] Campbell, A. "Subjective Measures of Well - being," American Psychologist. 31(1996): 117 - 124. https://doi.org/10.1037/0003-066X.31.2.117

[18]Ferrans, C.E. and M.J. Powers. "Quality of Life Index: Development and Psychometric Properties," Advanced in Nursing Science. 8, 10(1985): 15-24. https://doi.org/10.1097/00012272-198510000-00005

[19] Lewis, F. "Experienced Personal Control and Quality of Life in Late - stage Cancer Patients," in Nursing Research. pp. 113 Oxford: University of oxford, 1982.

[20] Maslow, A.H. (1943). "A theory of human motivation". Psychological Review. 50 (4): 370-96. Doi:10.1037/h0054346 - via psychclassics.yorku.ca. https://doi.org/10.1037/h0054346

[21] Maslow, a (1954). Motivation and personality. New York, NY: Harper. ISBN 0-06-041987-3.

[22] UNESCO. "Indicator of Environmental Quality of Life," in Research and Papers in Social Science. pp. 89 Paris: UNESCO, 1978.

[23] Wallace, Shron. Identification of Quality of Life Indicators for use in Family Planning Programs in Developing Countries.America: University of Pennsylvania, 1994.

[24] World Health Organization. The Ottawa Charter for Health Promotion. Geneva: World Health Organization, 1996.

[25]Zhan, L. "Quality of Life: Conceptual and Measurement Issues," Journal of Advanced Nursing. 17, 7(1992): 795 - 800. https://doi.org/10.1111/j.1365-2648.1992.tb02000.x 